\title{
The beginning of a new stage
}

\section{El comienzo de una etapa}

\author{
Roberto González-Salinas ${ }^{1 *}$ Nallely Ramos-Betancourt ${ }^{2}$, Juan C. Serna-Ojeda², and Raúl Vélez-Montoya ${ }^{2}$ \\ ${ }^{1}$ Chief Editor; ${ }^{2}$ Coeditor, Revista Mexicana de Oftalmología, Mexico City, Mexico
}

With this issue, we are starting a new era for the Mexican Journal of Ophthalmology (RMO), where a new board of directors has taken over for the next five years together with our publishing house Permanyer.

Over the last 20 months, we have been living a worldwide healthcare contingency, which no doubt has made a great impact not only on the way we practice ophthalmology, but also on how we interact in all the spheres of our routine clinical practice. Online learning and virtual meetings have turned out to be essential, resulting in both longer times spent in front of a screen, and the corresponding lack of interaction in general. However, we feel privileged to have had the opportunity to rise to the challenge posed by this change in the current paradigm.

In this "new normal" we now live by in front of a computer screen, the RMO will seek ways to get closer to its readers through better online spreading. Also, by using social networks, promoting greater use of new technologies that provide further opportunities to interact and have a presence on different forums, thus working as a link among the RMO, the authors, and the readers.

In this new chapter, we want to share the objectives we have set for the next five years. Our primary objective is to index the RMO on PubMed/MEDLINE and the Web of Science. With the previous board of directors, it was possible to raise the score required for this purpose from 3.0 to 3.5 , consolidating a great achievement in this sense and getting extremely closer to the approval score of 3.75 . Overall, greater priority will be given to work on the weak points of the previous evaluation to increase the chances of reaching favorable results.

A further objective is to consolidate the availability of articles in both Spanish and English through our online platform, which will contribute to the visibility of our journal and penetration factor worldwide. Emphasis will be laid on attracting original articles and systematic reviews to increase the number of tools available to make the reviews more agile and to look for new ways of giving recognition to the reviewers' work when evaluating scientific articles by allowing transparent and trustworthy connections among the investigators, the manuscripts, and the reviewers.

With these objectives in mind, the incoming board of directors, together with a working group including Dr. Nallely Ramos Betancourt, Dr. Juan Carlos Ojeda Serna, and Dr. Raúl Vélez Montoya as RMO associate editors, and myself will bear the responsibility of keeping the quality standards that have been the trademark
Disponible en internet: 31-01-2022 www.rmo.com.mx Rev Mex Oftalmol (Eng). 2022;96(1):1-2 (http://creativecommons.org/licenses/by-nc-nd/4.0/). 
of our journal. In addition to the new board of directors, both the national and the international has been renewed too, to achieve the goals set for this new period.

Finally, it is my privilege to extend our recognition to the outgoing board, headed by Dr. Manuel Alejandro Garza León. There is no doubt that this board has managed to hold the $R M O$ to the highest editorial standards during its administration. A board of directors I have had the privilege to be a part of during the last five years. All my gratitude to the board members. Therefore, we are truly proud to rise to the challenges posed by the present time and lead the RMO into a new chapter. 